\title{
Central Nervous System Imaging in Mitochondrial Disorders
}

\author{
Josef Finsterer
}

\begin{abstract}
Imaging of central-nervous-system (CNS) abnormalities is important in patients with mitochondrial disorders (MCDs) since the CNS is the organ second most frequently affected in MCDs and some of them are potentially treatable. Clinically relevant imaging techniques for visualization of CNS abnormalities in MCDs are computed tomography, magnetic resonance imaging, and MRspectroscopy. The CNS abnormalities in MCDs visualized by imaging techniques include stroke-like lesions with cytotoxic or vasogenic edema, laminar cortical necrosis, basal ganglia necrosis, focal or diffuse white matter lesions, focal or diffuse atrophy, intra-cerebral calcifications, cysts, lacunas, hypometabolisation, lactacidosis, hemorrhages, cerebral hypo- or hyperperfusion, intra-cerebral artery stenoses, or moyamoya syndrome. The CNS lesions may proceed with or without clinical manifestations, why neuroimaging should be routinely carried out in all MCDs to assess the degree of CNS involvement. Some of these lesions may remain unchanged for years, some may show contiguous spread and progression, but some may even disappear, spontaneously or in response to medication. Dynamics of Stroke-like lesions may be positively influenced by L-arginine, dichloracetate, steroids, edavarone, or antiepileptics. Symptomatic treatment of CNS abnormalities in MCD patients may positively influence their outcome.
\end{abstract}

RÉSUMÉ: Imagerie du système nerveux central dans les maladies mitochondriales. L'imagerie des anomalies du système nerveux central (SNC) est importante chez les patients atteints de maladies mitochondriales (MMC) parce que le SNC est le deuxième organe le plus souvent atteint dans les MMC et parce que certaines de ces maladies peuvent être traitables. Les techniques d'imagerie qui sont cliniquement pertinentes pour la visualisation des anomalies du SNC dans les MMC sont la tomodensitométrie, l'imagerie par résonance magnétique et la spectroscopie par résonance magnétique. Les anomalies du SNC dans les MMC qui sont visualisées par les techniques d'imagerie sont les lésions qui ressemblent à un accident vasculaire cérébral (LRAVC) avec oedème cytotoxique ou vasogénique, la nécrose corticale laminaire, la nécrose des noyaux gris centraux, les lésions focales ou diffuses de la substance blanche, l'atrophie focale ou diffuse, les calcifications intra-cérébrales, les kystes, les lacunes, l'hypométabolisme, l'acidose lactique, les hémorragies, l'hypoperfusion ou l'hyperperfusion cérébrale, les sténoses artérielles intra-cérébrales et le syndrome de Moya-Moya. Comme les lésions du SNC peuvent être accompagnées de manifestations cliniques ou être silencieuses, la neuroimagerie devrait être faite de routine chez tous les patients atteints d'une MMC pour évaluer le degré d'atteinte du SNC. Certaines de ces lésions peuvent demeurer stables pendant des années, certaines peuvent s'étendent de proche en proche alors que d'autres peuvent même disparaître spontanément ou sous l'effet du traitement. La dynamique des LRAVC peut être influencée favorablement par la L-arginine, le dichloracétate, les stéroïdes, l'edavarone ou les antiépileptiques. Le traitement symptomatique des anomalies du SNC chez les patients atteints de MMC peut influencer favorablement l'issue clinique.

Can. J. Neurol. Sci. 2009; 36:143-153

Mitochondrial disorders (MCDs) are usually multisystem diseases with onset between birth and senescence affecting the peripheral nervous system (PNS), the central nervous system (CNS), endocrine glands, heart, ears, eyes, gastrointestinal tract, liver, kidneys, bone marrow, dermis, or arteries, alone or in combination $^{1,2}$. Mitochondrial disorders usually take a progressive course: initially single organ manifestation turns into multi-system manifestation during the disease course. Various combinations of affected organs constitute mitochondrial syndromes (syndromic MCDs), for which well known acronyms have been adopted (Table 1). The MCDs are due to mutations in the mitochondrial DNA (mtDNA, mitochondrial MCDs) or nuclear DNA (nDNA, nuclear MCDs), impairing the function of the respiratory-chain, oxydative phosphorylation, pyruvate dehydrogenase complex (PDC), or beta-oxidation. Nuclear
MCDs are predominantly seen in children and mtDNA mutations particularly in adults.

The second most frequently affected organ in MCDs, alone or in combination, is the $\mathrm{CNS}^{3}$. Frequently, the CNS is affected together with the skeletal muscles for which the term "encephalomyopathy" has been coined 4 . Clinical CNS manifestations may go along with or without abnormal imaging

\footnotetext{
From Krankenanstalt Rudolfstiftung, Vienna, Austria, Europe

Received May 22, 2008. Final Revisions Submitted October 20, 2008. Correspondence to: Josef Finsterer, Postfach 20, 1180 Vienna, Austria, Europe.
} 
Table 1: Syndromatic mitochondrial disorders

\begin{tabular}{|c|c|}
\hline MELAS & $\begin{array}{l}\text { Mitochondrial encephalomyopathy, } \\
\text { lactacidosis, stroke-like episodes }\end{array}$ \\
\hline MERRF & Myoclonic epilepsy with ragged red fibers \\
\hline LHON & Leber's hereditary optic neuropathy \\
\hline LLS & $\begin{array}{l}\text { Leigh-like syndrome (subacute necrotizing } \\
\text { encephalomyelitis) }\end{array}$ \\
\hline LS & Leigh syndrome \\
\hline MILS & Maternally inherited Leigh syndrome \\
\hline KSS & Kearns Sayre syndrome \\
\hline CPEO & Chronic progressive external ophthalmoplegia \\
\hline PS & Pearson syndrome \\
\hline MNGIE & $\begin{array}{l}\text { Mitochondrial neuro-gastro-intestinal } \\
\text { encephalomyopathy }\end{array}$ \\
\hline SANDO & $\begin{array}{l}\text { Sensory ataxic neuropathy, dysarthria, } \\
\text { ophthalmoplegia }\end{array}$ \\
\hline MTS & Mohr-Tranebjaerg syndrome \\
\hline NARP & $\begin{array}{l}\text { Neurogenic muscle weakness, ataxia, and } \\
\text { retinitis pigmentosa }\end{array}$ \\
\hline FA & Friedreich ataxia \\
\hline AHD & $\begin{array}{l}\text { Alpers Huttenlocher disease (progressive } \\
\text { infantile poliodystrophy) }\end{array}$ \\
\hline MDS & Mitochondrial depletion syndrome \\
\hline MSL & Multiple systemic lipomatosis \\
\hline
\end{tabular}

studies and vice versa. The following review aims to give an overview on recent advances and current knowledge about imaging of CNS abnormalities, including morphology, frequency, and prognosis, in patients with MCDs, relevant for the daily routine.

\section{Diagnosis of MCDs}

Diagnosing MCDs relies on clinical, chemical, electrophysiological, histological, biochemical, and genetic investigations. Clinical findings suggesting an MCD include short stature, facial dysmorphism, a history of migraine, strokelike episodes, seizures, cognitive decline, impaired hearing, impaired ocular motility, impaired vision, thyroid dysfunction, hypoparathyroidism, diabetes mellitus, hyponatriemia, hypogonadism, cardiomyopathy, impulse generation or propagation abnormalities, vomiting, gastrointestinal pseudo-obstruction, diarrhea, hepatopathy, anemia, leucopenia, thrombocytopenia, renal insufficiency, myopathy, neuropathy, neuronopathy, or skin changes. Blood chemical investigations additionally may show increased creatine-kinase, lactate, or pyruvate. Urine levels of amino acids and organic acids may be reduced. Lactate and pyruvate may be also elevated in the cerebro-spinal fluid. Nerve conduction studies may indicate polyneuropathy or neuronopathy and electromyography may show myogenic, neurogenic or non-specific changes. Visually or acoustically evoked potentials and electroretinography may be abnormal. Neuroimaging may show abnormalities as described in this review. Muscle biopsy may show ragged-red muscle fibers, reduced cytochrome-C activity, increased SDH-activity, or abnormal mitochondria. Most important for diagnosing MCDs are biochemical investigations of the skeletal muscle or other tissues showing reduced activities of respiratory chain complexes or the PDC. The diagnosis is confirmed by demonstration of a mutation in nDNA or nDNA located genes.

\section{Clinical CNS manifestations of MCDs}

Clinical CNS manifestations of MCDs include almost all known CNS abnormalities of other cause (Table 2). The CNS abnormalities in MCDs may result from direct affection on the cerebrum or the supplying vasculature (primary CNS manifestations) or from secondary affection on the CNS by a non-CNS MCD abnormality (secondary CNS manifestations). Secondary CNS manifestations in MCDs include Hashimoto encephalopathy ${ }^{5}$, diabetic encephalopathy, hepatic encephalopathy, renal encephalopathy, arteriosclerosis from arterial hypertension, hyperlipidemia, stroke from extra- or intracerebral stenoses or cardiac embolism, neuronal damage at the infarcted area in stroke-like episodes (SLEs) from lactacidosis ${ }^{6}$, or drugs, which impair mitochondrial functions ${ }^{7}$. Clinical CNS manifestations of MCDs may be associated with or without morphological abnormalities on imaging studies or vice versa.
Table 2: Clinical CNS manifestations in MCDs

Psychiatric abnormalities

Neuropsychological impairment

Stroke or stroke-like-episodes (SLE)

Migraine or migraine-like headache

Epilepsy

Movement disorders, including Parkinson syndrome

Tremor

Dystonia

Chorea

Spasticity

Ataxia

Muscle hypotonia

Dysarthria

Dysphagia

Nystagmus

Sensory abnormalities due to dorsal column loss

Temperature dysregulation (including fever)

Sleep apnea syndrome

Abnormal breathing patterns or apnea Hypothalamic-pituitary abnormalities 


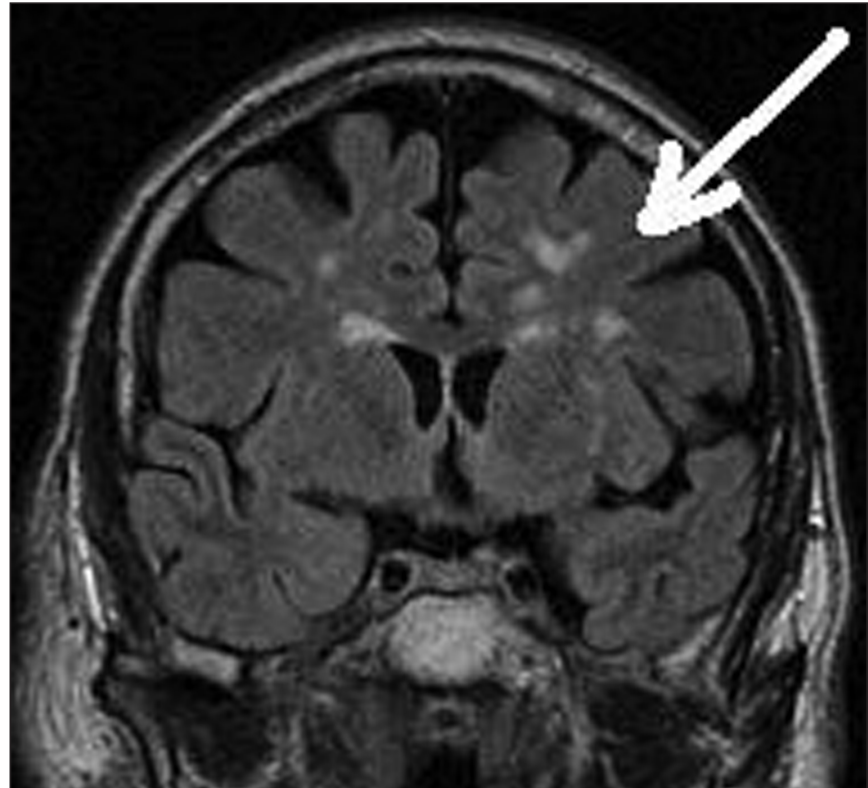

Figure 1: T2-weighted cerebral MRI (FLAIR) of a patient with nonsyndromic MCD (myopathy, Parkinson syndrome) showing multiple white matter lesions, initially misinterpreted as "vascular" despite the absence of cardiovascular risk factors.

\section{Typical CNS abnormalities in MCD patients}

\section{Demyelination. white matter lesions}

The most frequent finding in MCDs are focal or widespread white matter lesions (Figure 1), showing up as high signal on T2 or fluid-attenuated inversion recovery (FLAIR) images on magnetic resonance imaging (MRI) $)^{8,9}$. They may manifest as disseminated glial spots or as widespread, confluent lesions, like in leucodystrophy ${ }^{10}$. They may particularly involve the subcortical, central, or periventricular white matter ${ }^{10}$. White matter lesions may also be found in the basal ganglia ( $\mathrm{N}$. caudatus, putamen, globus pallidus), midbrain, pons, or cerebellum $^{11,12}$. Sometimes white matter lesions are found also in watershed regions ${ }^{13}$. Occasionally, cyst-like lesions occur within abnormal white matter ${ }^{14}$. White matter lesions have been described in patients with MELAS ${ }^{15}, \mathrm{LS}^{16-19}, \mathrm{LHON}^{20,21}, \mathrm{KSS}^{21}$, MNGIE $^{12}$, or non-syndromic MCD ${ }^{22,23}$. Also the chronic stage of stroke-like-lesions (SLL) or endstages of cytotoxic edema may manifest as white matter lesions. An increased blood-brain barrier permeability has been speculated to cause leucodystrophy in $\mathrm{MNGIE}^{10}$. There is no strong correlation between the extent of white matter involvement and the clinical manifestations but in single patients cerebral functions deteriorate with progressive extension of the cerebral lesions ${ }^{14}$. Generally, leucencephalopathy of unknown etiology with a complex neurological picture and multi-system involvement should lead the clinician to suspect a $\mathrm{MCD}^{14}$.

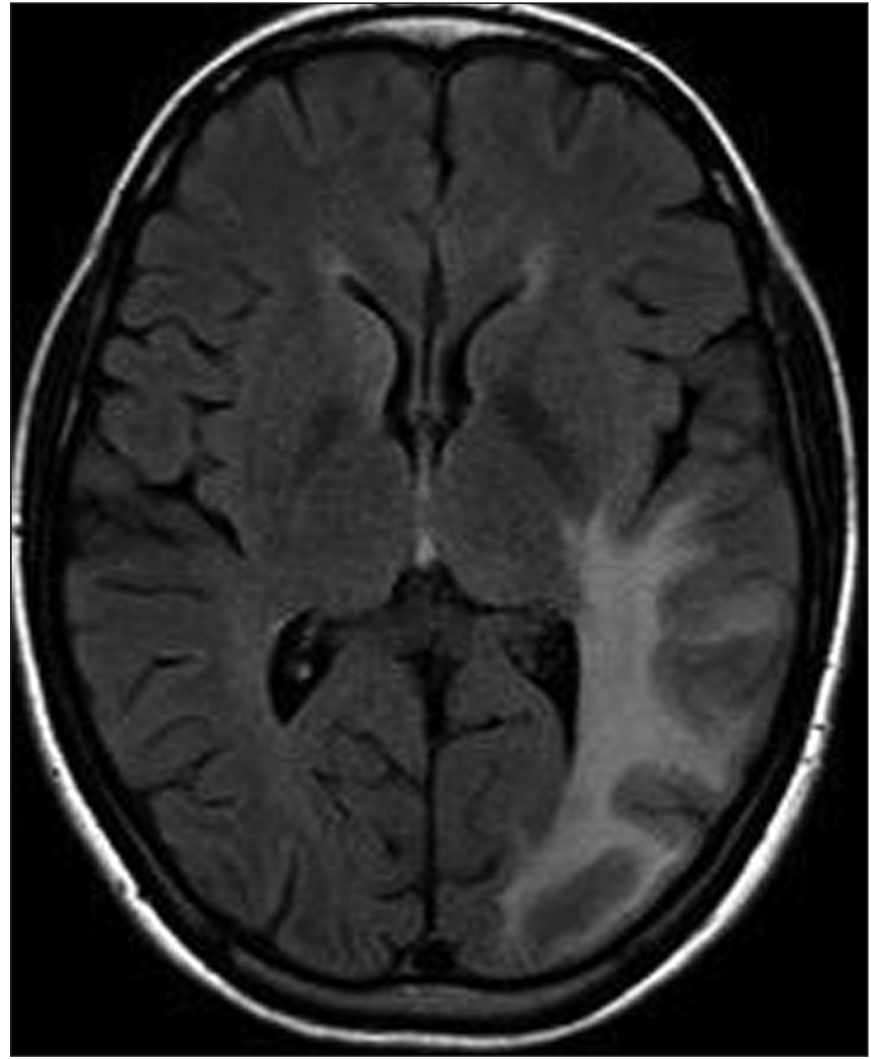

Figure 2: T2-weighted cerebral MRI (FLAIR) of a patient with MELAS syndrome (epilepsy, migraine, short stature, stroke-like episodes, lactacidosis) showing a hyperintense lesion in the left parieto-occipital area (stroke-like lesion).

\section{Stroke-like lesions (SLLS)}

Stroke-like lesions are regarded as manifestations of a vasogenic edema, which does not conform to a distinct vascular territory, concerns the white and grey matter, and shows dynamic changes in intensity and extensiveness over weeks, months, or years ${ }^{24}$. In the acute stage SLLs present as T2-hyperintensities, particularly located in the occipital, parietal, or temporal lobes but occasionally also in the frontal areas (Figure 2) ${ }^{25-29}$. Occasionally, also the deep grey matter may be involved (Figure $3)$. Stroke-like lesions show progressive spread into the neighboring areas already during the first days after onset ${ }^{30,31}$. Unique features of SLLs in the acute stage, in addition to progressive spread, are focal periodic epileptiform discharges, focal hyperperfusion, seen on SPECT studies ${ }^{24}$ and perfusion weighted MRI, and laminar cortical necrosis $(\mathrm{LCN})^{24}$. Some reports also demonstrated restricted diffusion within SLLs ${ }^{32-35}$. The SLLs usually progress up to several weeks after onset ${ }^{36}$. Clinical manifestations of SLLs are known as SLEs and include focal motor or sensory deficits, including hemiparesis, hemiataxia, hemianopsia, bilateral visual loss, and hemi- 


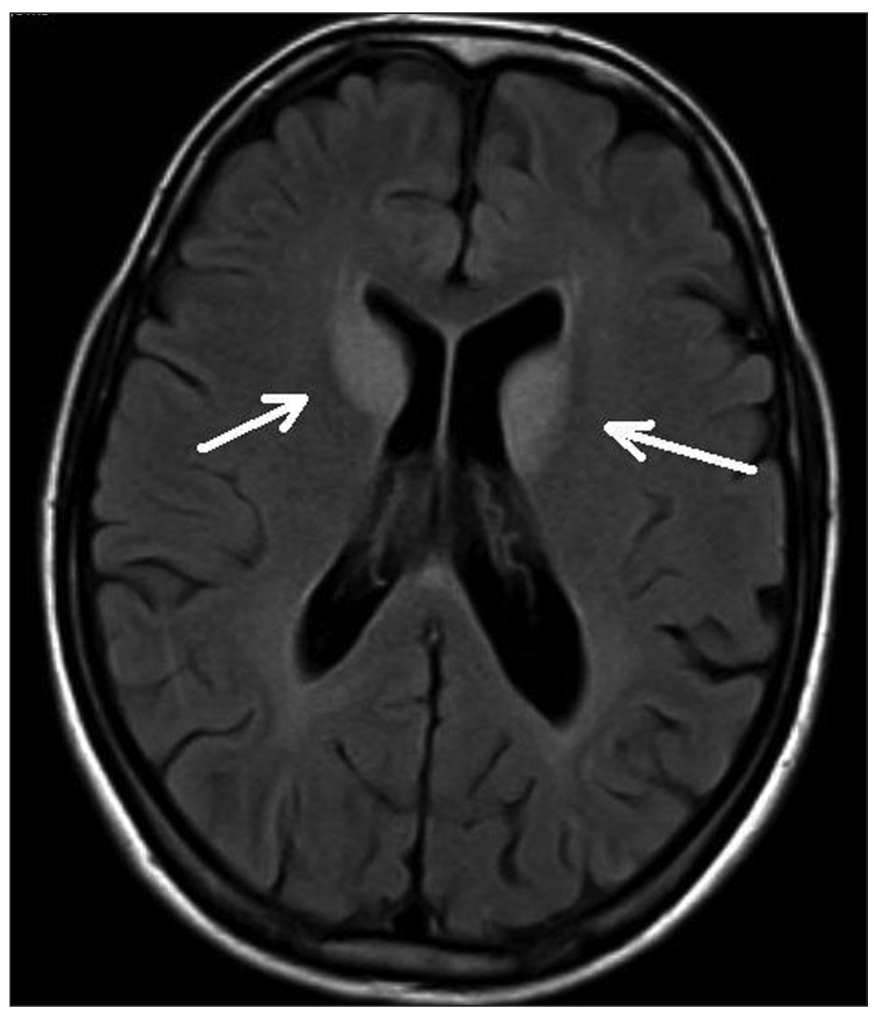

Figure 3: T2-weighted cerebral MRI (FLAIR) of a patient with MELAS syndrome showing hyerintense lesions in both caudate heads and slight leucaraiosis eight years after onset $(T R=300, T E=6000)$.

hypesthesia, which often disappear without sequelae or seizures $^{37}$. The SLEs are frequently transient, non-disabling, and often have a better prognosis than manifestations of an ischemic lesion. Since the clinical manifestations of SLLs mimic cerebral ischemia, they may be easily mixed up with ischemic stroke.

\section{Laminar cortical necrosis}

Laminar cortical necrosis (LCN) is a rare imaging and histopathological finding in MCDs, related to conditions of cerebral energy depletion, such as hypoxia, ischemia, or hypoglycemia, either in the perinatal period or later in life and with an increased risk to develop spasticity ${ }^{38}$. Laminar cortical necrosis may also occur in patients with decompensated hepatopathy due to hyperammonemia, ischemic stroke, moyamoya syndrome, meningoencephalitis, shaken baby syndrome, epileptic state, citrullinemia, or posterior reversible encephalopathy syndrome. The syndromic MCD most frequently associated with LCN is MELAS syndrome (Figure 4). Laminar cortical necrosis has been also described in a single patient with LS. Morphological features of LCN in MCDs are not at variance to those of LCN in non-MCDs. Clinical correlates of a LCN are spastic motor deficits, decreased intellectual capacity, aphasia, hemianopsia, sensory disturbances, or epilepsy ${ }^{39}$.

\section{Ischemic strokes}

Ischemic stroke in MCDs most frequently derives from secondary involvement of extra- or intra-cranial arteries by one of the extracerebral manifestations of an MCD, such as diabetes, arterial hypertension, hyperlipidemia, or cardiac involvement, including atrial fibrillation, cardiomyopathy, or left ventricular hypertrabeculation. Involvement of the endothelium or the vascular smooth muscle cells by the underlying metabolic defect may additionally cause stenosis of small arteries, arterioles or capillaries, resulting in small vessel disease, or lacunar ischemic stroke. Ischemic stroke in MCDs does not differ clinically or morphologically from ischemic stroke in patients without a MCD.

\section{Basal ganglia necrosis}

Symmetric necrosis of the basal ganglia, thalami, diencephalon, cerebellum, brainstem, or the spinal cord, showing up as T2-hyperintensities, is the imaging hallmark of Leigh syndrome (LS) and Leigh-like syndrome (LLS) (Figure 5) $)^{18,40-44}$.

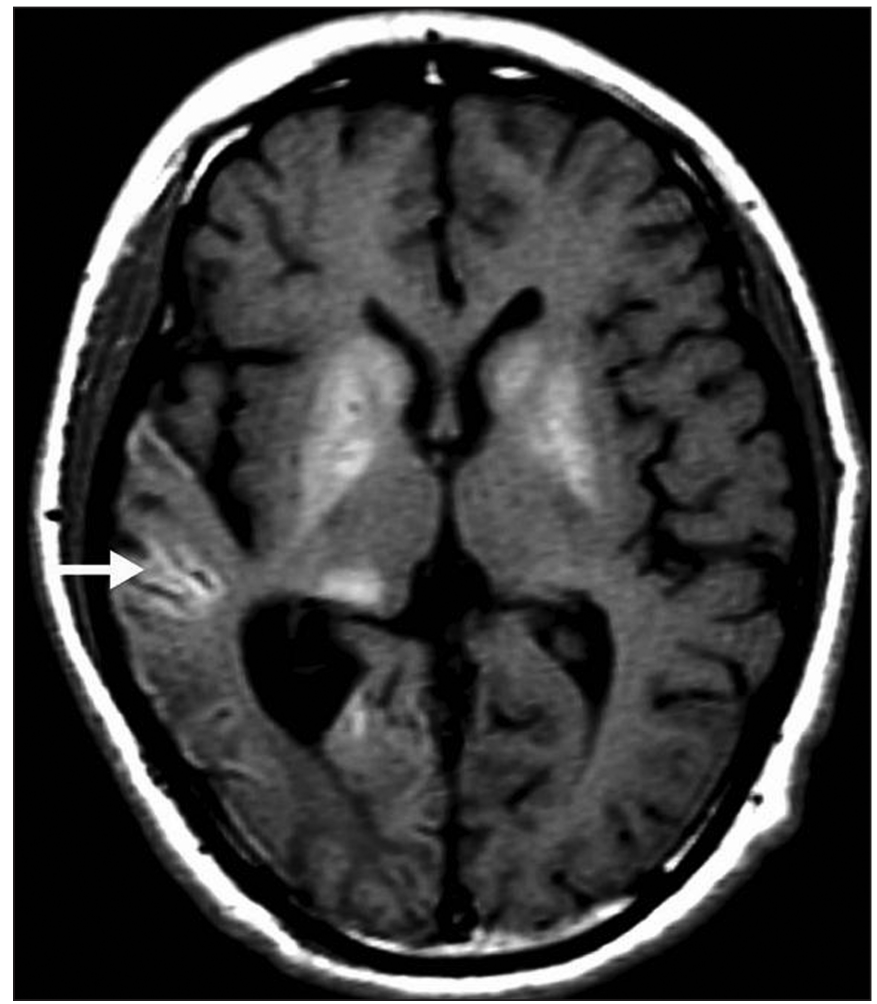

Figure 4: T1-weighted MRI of patient with MELAS syndrome showing gyriform hyperintensity in the right temporoparietal region, which is consistent with laminar cortical necrosis. Additionally, there is high signal in the basal ganglia compatible with complex calcium deposition (reprinted with permission from the J of Neuroophthalmology [Bi et al, Evolution of brain imaging abnormalities in mitochondrial encephalomyopathy with lactic acidosis and stroke-like episodes. J Neuroophthalmol. 2006;26:251-6]. 
Table 3: Imaging methods to visualize CNS abnormalities in MCD patients

\begin{tabular}{ll}
\hline & Usefulness \\
X-ray & $*$ \\
Transcranial Doppler imaging & $*$ \\
Cerebral computed tomography & $* * *$ \\
Magnetic resonance imaging & $* * *$ \\
$\quad$ T1 & $* *$ \\
T2 & $* * *$ \\
$\quad$ FLAIR & $* * *$ \\
T2* & $* * *$ \\
$\quad$ Diffusion weighted imaging & $* * *$ \\
$\quad$ ADC & $* * *$ \\
$\quad$ Angiography & $* *$ \\
$\quad$ H- or P-spectroscopy & $* * *$ \\
$\quad$ Diffusion tensor imaging & $*$ \\
Digital subtraction angiography & $*$ \\
SPECT & $*$ \\
PET & $*$ \\
\hline
\end{tabular}

*: minor importance, **: useful, ***: most relevant; ADC: apparent diffusion constant

These lesions are typically progressive in terms of extension and density. Usually, the basal ganglia are affected before involvement of the brainstem ${ }^{40}$. After initial involvement of the putamen, globi pallidi, caudate nuclei, or the thalami, the substantia nigra, peri-aqueductal gray matter, inferior colliculi, inferior olivary nuclei, or reticular formation may become additionally involved ${ }^{40}$. In the advanced stages of LS, white matter involvement additionally develops ${ }^{40}$. There is no correlation between these lesions on imaging and the clinical course or age at onset ${ }^{40}$. Some patients may show iron deposition within the basal ganglia and others may develop bilateral basal ganglia degeneration, as in Leber's hereditary optic neuropathy $(\mathrm{LHON})^{45}$.

\section{Atrophy}

Cerebral atrophy is a frequent finding on CNS imaging in MCDs and may be categorized as focal or diffuse, cortical or subcortical, supratentorial or infratentorial, primary or secondary after SLLs. Cortical atrophy may also develop in the chronic stage of $\mathrm{LCN}^{46}$. Cortical atrophy is associated with cognitive impairment on neuropsychological testing in the majority of the $\operatorname{cases}^{47,48}$. Diffuse cortical atrophy occurs in up to one third of the patients with encephalomyopathy ${ }^{10}$. Some patients with LS may develop predominant cerebellar atrophy with or without cerebral atrophy ${ }^{10,49}$. Isolated cerebellar atrophy has been also described in Kearns-Sayre syndrome (KSS), chronic progressive external ophthalmoplegia (CPEO), myoclonic epilepsy with ragged red fibers (MERRF) syndrome, and Alpers syndrome ${ }^{10,50}$. Focal atrophy may also involve the corpus callosum, the caudate nucleus, the basal ganglia, or the parietal, temporal, or frontal lobe. Atrophy may be the sole imaging finding in up to a quarter of the patients with MCDs ${ }^{50}$.

\section{Hemorrhages}

Cerebral hemorrhages in MCDs with CNS involvement may present as cortical or subcortical microhemorrhages but only rarely as severe intra-cerebral mass bleeding with mass effect, or subarachnoid hemorrhage. Microhemorrhages may be due to vascular lesions from endothelial swelling or due to lesions of the blood brain barrier. Microhemorrhages are a non-specific imaging feature in MCDs but have been most frequently described in patients with MELAS syndrome, particularly with laminar cortical necrosis, MERRF syndrome, and nonsyndromic MCDs.

\section{Cysts or lacunas}

Intra-cerebral cysts may develop after ischemic, lacunar stroke, within white matter lesions, or as a consequence of developmental abnormalities ${ }^{51,52}$. Cystic cerebral lesions visible on MRI were particularly reported in patients with MELAS, MERRF, and LS. Lacunas in the basal ganglia are a frequent feature of syndromic, or non-syndromic MCDs.

\section{Cerebral developmental abnormalities}

Association of MCDs with cerebral developmental abnormalities are rare ${ }^{51}$. Single cases with MCDs have been described, in which imaging studies revealed microcephaly or neuromigrational abnormalities, such as subependymal cysts, leptomeningeal or subcortical heterotopia (leptomeningeal heterotopia), polymicrogyria (particularly in MELAS) $)^{22,51,52}$, grossly thickened or undifferentiated cortex ${ }^{51}$, tuberous sclerosis $^{53}$, multifocal cerebral calcifications ${ }^{51}$, agenesis of the corpus callosum, or spongyform changes of the brainstem or cerebellum $^{51}$. Calcifications are most frequently located within the basal ganglia, uni- or bilaterally, but may occasionally occur in other locations. Basal ganglia calcifications are not restricted to a particular MCD but may occur with most of the known syndromes, most frequently, however, with MELAS or $\mathrm{KSS}^{48,54}$. In MELAS the most frequent location of the calcifications is the caudate nucleus, putamen, globus pallidus, or thalamus ${ }^{51}$.

\section{Cerebral artery stenoses and moyamoya disease}

Moyamoya disease is characterized by spontaneous, progressive occlusion of the supraclinoidal internal carotid arteries and the proximal median or anterior cerebral arteries leading to the formation of extensive arterial collaterals at the base of the cerebrum ${ }^{34}$. Magnetic resonance angiography may reveal occlusion of the distal internal carotid arteries with development of a collateral circulation (moyamoya disease) and stenosis of the intracerebral arteries ${ }^{55}$. Only in single cases, however, moyamoya has been described in patients with $\mathrm{MCDs}^{34,56}$.

\section{Pituitary gland}

Endocrine abnormalities, such as hypothyroidism, hypoparathyroidism, diabetes, hypocorticism, or hypogonadism, are a frequent feature of syndromic and non-syndromic MCDs. Additionally, the pituitary gland may be affected, manifesting as hypopituitarism or morphological abnormalities of the pituitary gland on imaging studies. This is particularly the case with pituitary adenomas, which require surgical intervention after 
Table 4: Validity of imaging methods to detect distinct CNS abnormalities in MCD patients

\begin{tabular}{|c|c|c|c|c|c|c|c|c|c|c|c|}
\hline & $\mathrm{AT}$ & CALC & CYST & WML & SLL & BGNEC & $\mathrm{LCN}$ & STEN & CLAC & HYPPERF & MOYMO \\
\hline X-ray & - & + & - & - & - & - & - & - & - & - & - \\
\hline TCD & - & - & - & - & - & - & - & + & - & - & - \\
\hline $\mathrm{CT}$ & + & + & + & + & + & + & - & $+/-$ & - & $+/-$ & - \\
\hline MRI & + & - & + & + & + & + & + & $+/-$ & - & $+/-$ & + \\
\hline MRA & - & - & - & - & - & - & - & + & - & - & + \\
\hline MRS & - & - & - & - & - & - & - & - & + & - & - \\
\hline DSA & - & - & - & - & - & - & - & + & - & - & + \\
\hline SPECT & - & - & - & - & + & - & - & - & - & + & + \\
\hline PET & - & - & - & - & - & - & - & - & - & + & - \\
\hline
\end{tabular}

AT: atrophy, CALC: calcifications, CYST: cystic lesions, DSA: digital subtraction angiography, SPECT: single photon emission computed tomography, PET: positron emission tomography, SLL: stroke-like lesions, BGNEC: basal ganglia necrosis, LCN: laminar cortical necrosis, WML: white matter lesions, STEN: artery stenosis, CLAC: cerebral lactacidosis, TCD: transcranial Doppler sonography, HYPPERF:

hyperperfusionMOYMO: Moya Moya;

having become symptomatic. Though endocrine abnormalities are particularly found in patients with MELAS, KSS, and LS, they may occur in each of the MCDs.

\section{Methods to visualize CNS manifestations of MCDs}

All imaging methods used to visualize CNS abnormalities can be also applied to MCD patients (Table 3). Though all methods visualize certain aspects of CNS abnormalities, some are more important in the daily routine than others due to their different availability and sensitivity and specificity to detect certain abnormalities. Of minor importance is the ultrasound, despite its widespread availability. The most helpful techniques to visualize CNS abnormalities in MCDs are the CT and the MRI. SPECT and PET would be useful, but are hardly applied in the daily routine due to their restricted availability.

\section{Computed tomography $(\mathrm{CT})$}

Computed tomography scans are widely available and useful for showing focal or diffuse atrophy, calcifications, cysts or lacunas, ischemic lesions, hemorrhages, white matter lesions, demyelination, but have their limitations when trying to visualize other abnormalities, such as SLLs ${ }^{57}$, symmetric necrosis of the thalami, basal ganglia, diencephalon, or brainstem in patients with LS or LLS ${ }^{45}$. The CT may show diffuse atrophy or focal atrophy of the supratentorial cortex ${ }^{22}$ or the cerebellum ${ }^{58,59}$, focal or diffuse demyelination, uni- or bilateral calcifications of the basal ganglia, frequently observed in MELAS ${ }^{54,59}$, dentate nuclei, or the cerebellum ${ }^{59}$, vasogenic edema ${ }^{60,61}$, bilateral striatal necrosis ${ }^{59,62}$, malformations ${ }^{63}$ such as polymicrogyria ${ }^{52}$ or tuberous sclerosis ${ }^{53}$, or macro- or microhemorrhages.

\section{Magnetic resonance imaging (MRI)}

The most valuable tool to visualize CNS abnormalities in MCDs is the $\mathrm{MRI}^{50}$. Magnetic resonance imaging may show atrophy, SLLs, demyelination, ischemic lesions, hemorrhages, vasogenic edema, LCN, or leucencephalopathy. Acute SLLs manifest on MRI as widespread T2-hyperintensities particularly in the temporo-parietal region ${ }^{50}$. On diffusion weighted imaging (DWI) SLLs present as hyperintensities ${ }^{27-29,33,35,64,65}$. Diffusion weighted imaging is regarded as more sensitive than T2weighted images to demonstrate SLLs ${ }^{15}$. Contrary to ischemic lesions the apparent diffusion coefficient (ADC) is usually increased in acute SLE lesions ${ }^{27}$. The MRI may also show focal cytotoxic edema within a SLL in the acute or subacute stage, manifesting as hyperintensities on DWI but low ADC signals ${ }^{35}$. These lesions may be intermingled with cystic lesions in the chronic stage. SLL may either persist during years or may disappear after weeks, months, or years. Bilateral symmetric involvement of the deep grey matter can be found in up to $50 \%$ of patients with MCDs, most frequently in Leigh syndrome ${ }^{50}$. LCN on MRI is characterized by permanent, focal or diffuse cortical high signals on T1-weighted or FLAIR images, which follow the gyral anatomy of the cerebral cortex ${ }^{39}$. In the chronic stage cortical atrophy may develop ${ }^{46}$. In neonates with a MCD cerebral MRI may show agenesia of the corpus callosum, ventriculomegaly, diminished sulcal markings, shallow sulci, polymicrogyria, pachygyria with grossly increased thickness, subcortical or periventricular calcifications, or subependymal cysts $^{51}$. Perfusion-weighted imaging may show hyperintensities corresponding to hyperperfusion during the acute or subacute stage of SLL. Whether SPECT or PET studies are more apt to demonstrate hyperperfusion in MCDs than MRI has not been investigated so far. 


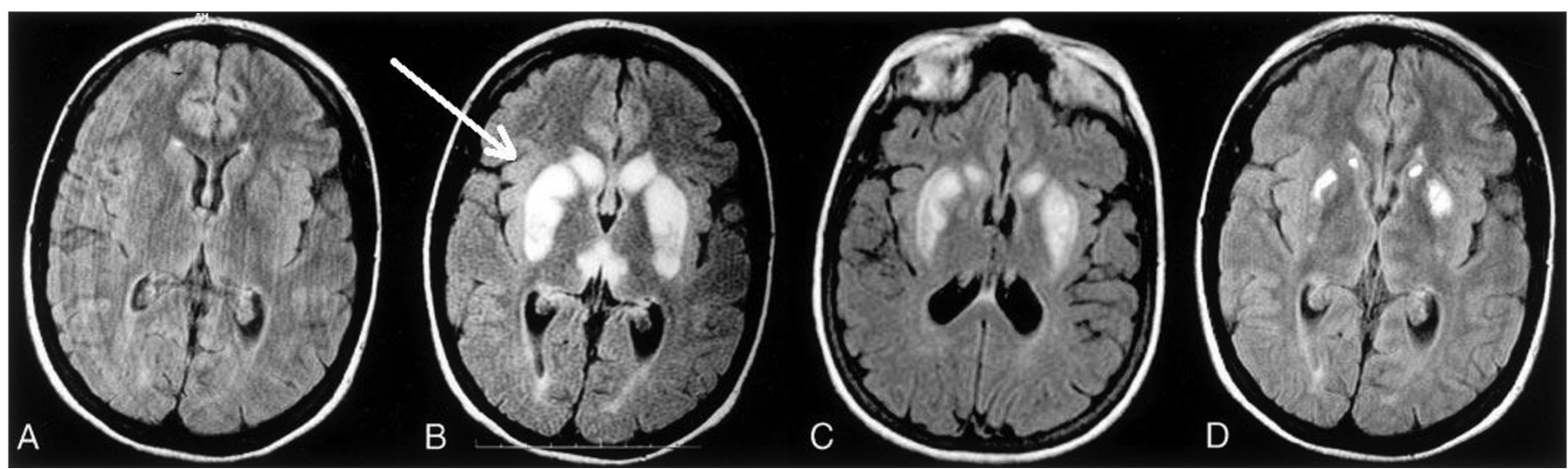

Figure 5: Sequential FLAIR images in a patient with Leigh syndrome showing normal findings at onset (A), bilaterally symmetric hyperintense lesions of the basal ganglia, $(B)$ a hyperintense lesion in the left parieto-occipital area $(C)$ and hyperintensities and swelling of caudate heads, putamina and external globus pallidus (D) [Goldenberg et al, 2003, with permission].

\section{MR-spectroscopy (MRS)}

Principally, two techniques are available for MRS, protonMRS (H-MRS) and phosphorus-MRS (P-MRS). H-MRS typically shows increased lactate and reduced $\mathrm{N}$-acetyl-aspartate (NAA), glutamate, myo-inositol, cholin, or creatine concentrations within the SLLs (Figure 6) ${ }^{66,67}$, most frequently occurring in patients with LS, MELAS, KSS, or MERRF ${ }^{10}$. Similar but less prominent alterations can be found in the grey matter $^{67}$. The most frequent finding on MRS in MCD with CNS involvement is an increased lactate peak ${ }^{15,18,33,65,68-83}$, which may precede the SLLs ${ }^{15}$. High levels of intra-ventricular lactate are usually associated with severe neurologic impairment ${ }^{6}$. In unaffected areas, the cholin peak, creatine peak, or NAA peak may be reduced ${ }^{22,70}$. In patients with LS high choline levels were seen in the white matter, most probably related to an ongoing demyelination process ${ }^{81}$. In MELAS patients MRS may show increased alanine and glucose concentrations ${ }^{82}$. In patients with PDC deficiency pyruvate may be increased ${ }^{82}$. Also succinate may be elevated in single MCD patients ${ }^{84}$. The MR spectroscopic imaging allows better spatial resolution than single voxel MRS. A disadvantage of single-voxel H-MRS is that mitochondrial dysfunction often has a patchy regional distribution why lactacidosis may be demonstrated in some areas but not in others ${ }^{10}$. In the absence of a structural abnormality on MRI, sampling of the basal ganglia for MRS is recommended ${ }^{10}$. The CSF or intra-cerebral lactate may not only be elevated in MCDs but also in CNS infections or CNS malignancies. Abnormal P-MRS was particularly reported in $\mathrm{LHON}^{85,86}$.

\section{MR-angiography (MRA)}

Magnetic resonance angiography may show short or extended stenoses of the extra- or intracranial arteries. The MRA may also indicate moyamoya syndrome as a rare manifestation of cerebral involvement of an MCD if there are bilateral stenoses of the supraclinoidal parts of the internal carotid arteries.

\section{Single photon emission computed tomography (SPECT)}

Investigations by SPECT have been rarely carried out in MCD patients and are conflicting. In patients with an ND1 defect the dopamine transporter SPECT was normal ${ }^{87}$. In MELAS patients with a SLE, the cerebral blood flow has been found increased on Tc-99m HMPAO cerebral SPECT ${ }^{88}$. In acute SLLs hyperperfusion has been documented within the lesions ${ }^{24}$. General hyperperfusion, most pronounced within SLLs, may be found even weeks after a SLE. On the contrary the cerebral blood flow may be decreased in patients with $\mathrm{CPEO}^{24,89}$. Irrespective of whether patients had or had not suffered from SLEs, SPECT may show multiple areas of asymmetrical hypoperfusion, particularly in the posterior or lateral cerebral regions, particularly the temporal lobes. Also crossed-cerebellar diaschisis has been reported ${ }^{89}$.

\section{Positron-emission-tomography (PET)}

Positron-emission-tomography studies have been only rarely applied in the diagnostic work-up of CNS involvement of MCDs. In a study on patients with POLG mutations loss of dopaminergic neurons has been demonstrated by $\mathrm{PET}^{90}$. PET studies in eight carriers of the A3243G mtDNA mutation showed widespread cortical and basal ganglia metabolic deficits ${ }^{91}$.

\section{Practical implications}

One of the most important clinical implications of CNS imaging is the differentiation between multiple sclerosis and MCD. Quite a number of MCD patients are diagnosed as multiple sclerosis since they fulfill the MRI diagnostic criteria but present clinically without spasticity, have polyneuropathy, or occur familiarly. Before diagnosing multiple sclerosis it is important to take findings of the clinical examination, family 


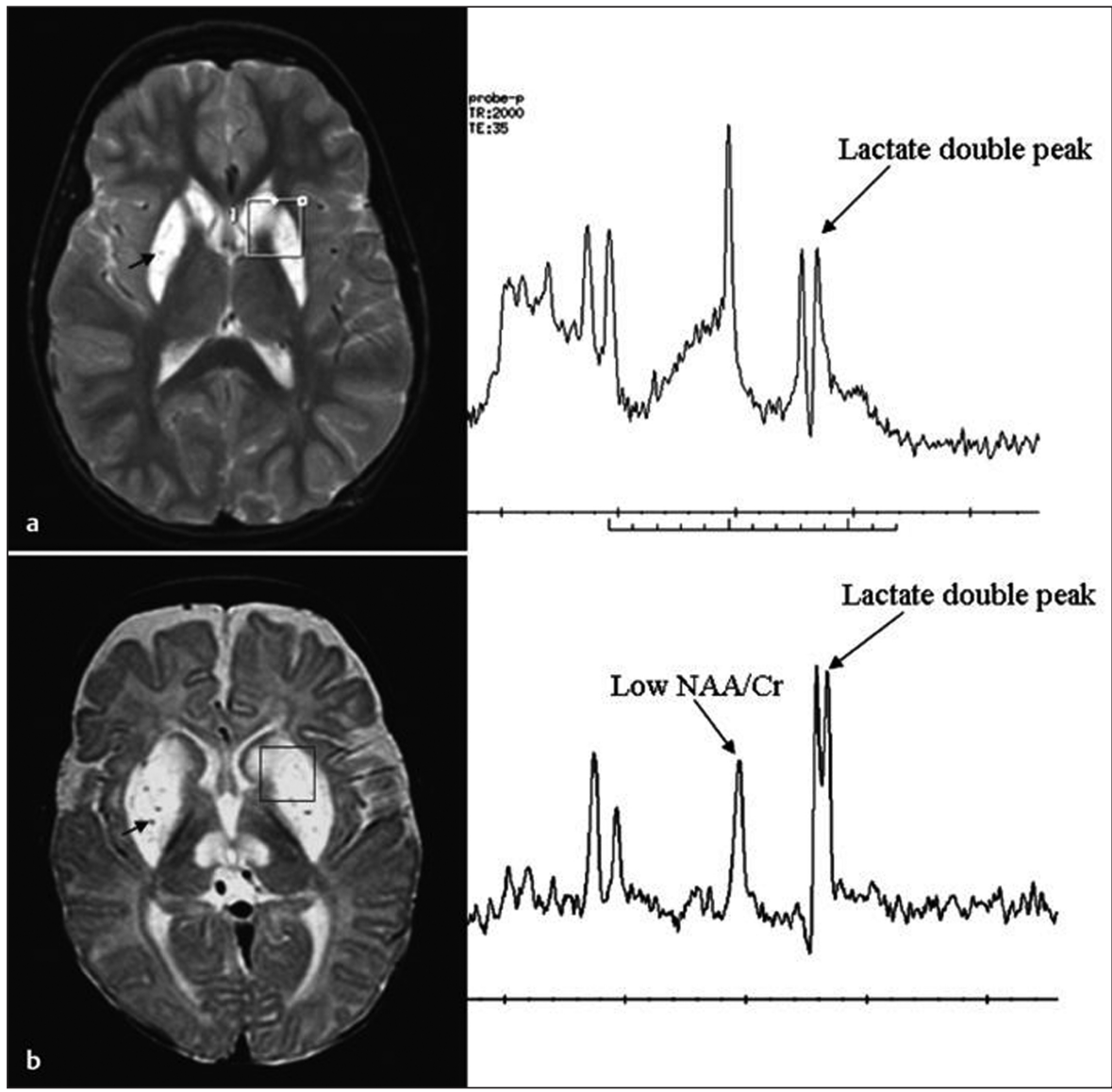

Figure 6: H-MRS from increased, homogenous signal in the striatum of a patient with Leigh-like syndrome showing a large lactate elevation (double peak) [Dinopoulos et al,, 2005, with permission] .

history, electrophysiology, and muscle biopsy into account. It is also important to differentiate between metabolic and ischemic lesions, since in the presence of SLLs antiepileptic therapy may be helpful, particularly if paroxysmal activity can be recorded on $\mathrm{EEG}^{24}$. The SLLs need to be distinguished from progressive, multifocal leucencephalopathy, associated with HIV-positives, BK-virus (BKV) or John Cunningham virus (JCV) infection, or side effects of immune-modulatory therapy with natalizumab or rituximab. Furthermore, it is important to consider MCDs as a differential in patients with juvenile stroke, Parkinson syndrome, other extra-pyramidal syndromes, dementia, psychosis, or epilepsy.

Since the prevalence of MCDs appears much higher than previously thought, particularly non-syndromic MCDs, they should be much more frequently considered as differentials. Indications for an MCD are the presence of CNS abnormalities (dementia, epilepsy, SLLs, ischemic strokes, migraine, cognitive decline, extra-pyramidal abnormalities, optic atrophy, spasticity, hypotonia, respiratory failure), PNS abnormalities (polyneuropathy, myopathy, anterior horn cell disease), endocrine abnormalities (short stature, hypopituitarism, pituitary adenoma, hypothyroidism, hypocorticism, hypogonadism, hypohyperparathyroidism, diabetes, osteoporosis), cardiac abnormalities (cardiomyopathy, left ventricular hypertrabeculation, Takotsubo syndrome, arrhythmias), ocular abnormalities (cataract, glaucoma, retinitis pigmentosa), otologic abnormalities (hypacusis, tinnitus, vertigo), gastrointestinal problems (hepatopathy, pancreatitis, vomiting, diarrhea), kidney problems (renal failure, renal cysts, hypokaliemia, hyponatriemia), hyperlipidemia, hematological abnormalities (anemia, thrombocytopenia, leukopenia, pancytopenia), dermatoses, or atherosclerosis.

\section{Conclusions}

Imaging methods are essential to visualize CNS abnormalities in MCDs. The most valuable among the various methods is MRI. Cerebral lactacidosis is best demonstrated by MR-spectroscopy. Mitochondrial disorders should be considered in the presence of a combination of key clinical features or key features on cerebral imaging, which may go along with or without clinical CNS abnormalities. Since the CNS is the second most frequently affected organ in MCDs and since the 
prevalence of MCDs is rapidly increasing because of increased awareness and sensibility for MCDs, clinicians and radiologists should consider MCDs more frequently as differentials of unexplained CNS imaging findings. Though CNS imaging is helpful to support the diagnosis of an MCD, investigations other than imaging are of paramount importance, before establishing the diagnosis of an MCD. The MCDs cannot be diagnosed using CNS imaging alone.

\section{REFERENCES}

1. Zeviani M, Carelli V. Mitochondrial disorders. Curr Opin Neurol. 2007;20:564-71.

2. Finsterer J. Mitochondriopathies. Eur J Neurol. 2004;11:163-86.

3. Finsterer J, Jarius C, Eichberger H. Phenotype variability in 130 adult patients with respiratory chain disorder. J Inher Metab Dis. 2001;24:560-76.

4. Leonard JV, Schapira AHV. Mitochondrial respiratory chain disorders I: mitochondrial DNA defects. Lancet. 2000;355: 299-304.

5. Berio A, Piazzi A. A case of Kearns-Sayre syndrome with autoimmune thyroiditis and possible Hashimoto encephalopathy. Panminerva Med. 2002;44:265-9.

6. Kaufmann P, Shungu DC, Sano MC, Jhung S, Engelstad K, Mitsis E, et al. Cerebral lactic acidosis correlates with neurological impairment in MELAS. Neurology. 2004;62:1297-302.

7. Ahn MS, Sims KB, Frazier JA. Risperidone-induced psychosis and depression in a child with a mitochondrial disorder. J Child Adolesc Psychopharmacol. 2005;15:520-5.

8. Gire C, Girard N, Nicaise C, Einaudi MA, Montfort MF, Dejode JM. Clinical features and neuroradiological findings of mitochondrial pathology in six neonates. Childs Nerv Syst. 2002;18:621-8.

9. Haas R, Dietrich R. Neuroimaging of mitochondrial disorders. Mitochondrion. 2004;4:471-90

10. Van Goethem G, Luoma P, Rantamaki M, Al Memar A, Kaakkola $\mathrm{S}$, Hackman P, et al. POLG mutations in neurodegenerative disorders with ataxia but no muscle involvement. Neurology. 2004;63:1251-7.

11. Millar WS, Lignelli A, Hirano M. MRI of five patients with mitochondrial neurogastrointestinal encephalomyopathy. Am J Roentgenol. 2004;182:1537-41.

12. Apostolova LG, White M, Moore SA, Davis PH. Deep white matter pathologic features in watershed regions: a novel pattern of central nervous system involvement in MELAS. Arch Neurol. 2005;62:1154-6.

13. Dinopoulos A, Cecil KM, Schapiro MB, Papadimitriou A, Hadjigeorgiou GM, Wong B, et al. Brain MRI and proton MRS findings in infants and children with respiratory chain defects. Neuropediatrics. 2005;36:290-301

14. Lerman-Sagie T, Leshinsky-Silver E, Watemberg N, Luckman Y, Lev D. White matter involvement in mitochondrial diseases. Mol Genet Metab. 2005;84:127-36.

15. Abe K. Cerebral lactic acidosis correlates with neurological impairment in MELAS. Neurology. 2004;63:2458.

16. Desguerre I, Pinton F, Nabbout R, Moutard ML, N'Guyen S, Marsac C, et al. Infantile spasms with basal ganglia MRI hypersignal may reveal mitochondrial disorder due to T8993G mtDNA mutation. Neuropediatrics. 2003;34:265-9.

17. Farina L, Chiapparini L, Uziel G, Bugiani M, Zeviani M, Savoiardo M. MR findings in Leigh syndrome with COX deficiency and SURF-1 mutations. Am J Neuroradiol. 2002;23:1095-100.

18. Rossi A, Biancheri R, Bruno C, Di Rocco M, Calvi A, Pessagno A, et al. Leigh Syndrome with COX deficiency and SURF1 gene mutations: MR imaging findings. Am J Neuroradiol. 2003;24: 1188-91.

19. Topcu M, Saatci I, Apak RA, Soylemezoglu F, Akcoren Z. Leigh syndrome in a 3-year-old boy with unusual brain MR imaging and pathologic findings. Am J Neuroradiol. 2000;21:224-7.

20. Lev D, Yanoov-Sharav M, Watemberg N, Leshinsky-Silver E, Lerman-Sagie T. White matter abnormalities in Leber's hereditary optic neuropathy due to the 3460 mitochondrial DNA mutation. Eur J Paediatr Neurol. 2002;6:121-3.

21. Vinkler C, Lev D, Kalish H, Watemberg N, Yanoov-Sharav M, Leshinsky-Silver E, et al. Familial optic atrophy with white matter changes. Am J Med Genet A. 2003 1;121:263-5.

22. Moroni I, Bugiani M, Bizzi A, Castelli G, Lamantea E, Uziel G. Cerebral white matter involvement in children with mitochondrial encephalopathies. Neuropediatrics. 2002;33: 79-85.

23. Weinstock A, Giglio P, Cohen ME, Bakshi R, Januario J, Balos L. Diffuse magnetic resonance imaging white-matter changes in a 15-year-old boy with mitochondrial encephalomyopathy. J Child Neurol. 2002;17:47-9.

24. Iizuka T, Sakai F, Ide T, Miyakawa S, Sato M, Yoshii S. Regional cerebral blood flow and cerebrovascular reactivity during chronic stage of stroke-like episodes in MELAS -- implication of neurovascular cellular mechanism. J Neurol Sci. 2007;257: 126-38.

25. Feng F, You H, Gao J, Li XZ, Meng CL, Sun HY, et al. Evaluation of mitochondrial encephalomyopathy with lactic acidosis and stroke-like episodes with magnetic resonance imaging and proton magnetic resonance spectroscopy. Chin Med Sci J. 2006; 21:234-8

26. Jian-Ren L. Precipitation of stroke-like event by chickenpox in a child with MELAS syndrome. Neurol India. 2005;53:323-5.

27. Kolb SJ, Costello F, Lee AG, White M, Wong S, Schwartz ED, et al. Distinguishing ischemic stroke from the stroke-like lesions of MELAS using apparent diffusion coefficient mapping. J Neurol Sci. 2003;216:11-5.

28. Ohshita T, Oka M, Imon Y, Watanabe C, Katayama S, Yamaguchi $\mathrm{S}$, et al. Serial diffusion-weighted imaging in MELAS. Neuroradiology. 2000;42:651-6.

29. Oppenheim C, Galanaud D, Samson Y, Sahel M, Dormont D, Wechsler B, et al. Can diffusion weighted magnetic resonance imaging help differentiate stroke from stroke-like events in MELAS? J Neurol Neurosurg Psychiatry. 2000;69:248-50.

30. Iizuka T, Sakai F, Kan S, Suzuki N. Slowly progressive spread of the stroke-like lesions in MELAS. Neurology. 2003;61:1238-44.

31. Kim HS, Kim DI, Lee BI, Jeong EK, Choi C, Lee JD, et al. Diffusion-weighted image and MR spectroscopic analysis of a case of MELAS with repeated attacks. Yonsei Med J. 2001;42: $128-33$.

32. Mizrachi IB, Gomez-Hassan D, Blaivas M, Trobe JD. Pitfalls in the diagnosis of mitochondrial encephalopathy with lactic acidosis and stroke-like episodes. J Neuroophthalmol. 2006;26:38-43.

33. Wang XY, Noguchi K, Takashima S, Hayashi N, Ogawa S, Seto H. Serial diffusion-weighted imaging in a patient with MELAS and presumed cytotoxic oedema. Neuroradiology. 2003;45:640-3.

34. Longo N, Schrijver I, Vogel H, Pique LM, Cowan TM, Pasquali M, et al. Progressive cerebral vascular degeneration with mitochondrial encephalopathy. Am J Med Genet A. 2008;146: 361-7.

35. Maeda K, Tatsumi M, Tahara M, Murata Y, Kawai H, Yasuda H. A case of stroke-like episode of MELAS of which progressive spread would be prevented by edaravone. Rinsho Shinkeigaku. 2005;45:416-21.

36. Bi WL, Baehring JM, Lesser RL. Evolution of brain imaging abnormalities in mitochondrial encephalomyopathy with lactic acidosis and stroke-like episodes. J Neuroophthalmol. 2006;26: 251-6.

37. Corda D, Rosati G, Deiana GA, Sechi G. "Erratic" complex partial status epilepticus as a presenting feature of MELAS. Epilepsy Behav. 2006;8:655-8.

38. van der Knaap MS, Smit LS, Nauta JJ, Lafeber HN, Valk J. Cortical laminar abnormalities--occurrence and clinical significance. Neuropediatrics. 1993;24:143-8.

39. Donaire A, Carreno M, Gómez B, Fossas P, Bargalló N, Agudo R, et al. Cortical laminar necrosis related to prolonged focal status epilepticus. J Neurol Neurosurg Psychiatry. 2006;77:104-6.

40. Arii J, Tanabe Y. Leigh syndrome: serial MR imaging and clinical follow-up. Am J Neuroradiol. 2000;21:1502-9. 
41. Bénit P, Slama A, Cartault F, Giurgea I, Chretien D, Lebon S, et al. Mutant NDUFS3 subunit of mitochondrial complex I causes Leigh syndrome. J Med Genet. 2004;41:14-7.

42. Chol M, Lebon S, Bénit P, Chretien D, de Lonlay P, Goldenberg A, et al. The mitochondrial DNA G13513A MELAS mutation in the $\mathrm{NADH}$ dehydrogenase 5 gene is a frequent cause of Leigh-like syndrome with isolated complex I deficiency. J Med Genet. 2003;40:188-91.

43. Horváth R, Abicht A, Holinski-Feder E, Laner A, Gempel K, Prokisch $\mathrm{H}$, et al. Leigh syndrome caused by mutations in the flavoprotein (Fp) subunit of succinate dehydrogenase (SDHA). J Neurol Neurosurg Psychiatry. 2006;77:74-6.

44. Martin MA, Blazquez A, Gutierrez-Solana LG, Fernández-Moreira $\mathrm{D}$, Briones P, Andreu AL, et al. Leigh syndrome associated with mitochondrial complex I deficiency due to a novel mutation in the NDUFS1 gene. Arch Neurol. 2005;62:659-61.

45. McFarland R, Taylor RW, Turnbull DM. The neurology of mitochondrial DNA disease. Lancet Neurol. 2002;1:343-51.

46. Bargalló N, Burrel M, Berenguer J, Cofan F, Buñesch L, Mercader JM. Cortical laminar necrosis caused by immunosuppressive therapy and chemotherapy. Am J Neuroradiol. 2000;21:479-84.

47. Barragan-Campos HM, Vallee JN, Lo D, Barrera-Ramírez CF, Argote-Greene M, Sánchez-Guerrero J, et al. Brain magnetic resonance imaging findings in patients with mitochondrial cytopathies. Arch Neurol. 2005;62:737-42.

48. Geldof K, Ramboer K, Goethals JM, Verhaeghe L. CT and MRI appearance of mitochondrial encephalopathy. JBR-BTR. 2007; 90:288-9.

49. Scaglia F, Wong LJ, Vladutiu GD, Hunter JV. Predominant cerebellar volume loss as a neuroradiologic feature of pediatric respiratory chain defects. Am J Neuroradiol. 2005;26:1675-80.

50. Kim J, Lee SK, Kim EY, Kim DI, Lee YM, Lee JS, et al. Neuroradiologic findings in children with mitochondrial disorder: correlation with mitochondrial respiratory chain defects. Eur Radiol. 2008;18:1741-8.

51. van Straaten HL, van Tintelen JP, Trijbels JM, van den Heuvel LP, Troost D, Rozemuller JM, et al. Neonatal lactic acidosis, complex I/IV deficiency, and fetal cerebral disruption. Neuropediatrics. 2005;36:193-9.

52. Keng WT, Pilz DT, Minns B, FitzPatrick DR. A3243G mitochondrial mutation associated with polymicrogyria. Dev Med Child Neurol. 2003;45:704-8

53. Walker M, Samii A, Bird T. Coexistence of tuberous sclerosis and Friedreich ataxia. J Neurol Sci. 2004;221:91-3.

54. Finsterer J. Central nervous system manifestations of mitochondrial disorders. Acta Neurol Scand. 2006;114:217-38.

55. Riggs JE, Schochet SS Jr, Fakadej AV, Riggs JE, Schochet SS Jr, Fakadej AV, et al. Mitochondrial encephalomyopathy with decreased succinate-cytochrome $\mathrm{c}$ reductase activity. Neurology. 1984;34:48-53.

56. Kotagal S, Peterson PL, Martens ME, Lee CP, Nigro M, Archer CR. Impaired NADH-CoQ reductase activity in a child with moyamoya syndrome. Pediatr Neurol. 1988;4:241-4.

57. Iizuka T, Sakai F, Suzuki N, Hata T, Tsukahara S, Fukuda M, et al. Neuronal hyperexcitability in stroke-like episodes of MELAS syndrome. Neurology. 2002;59:816-24.

58. Petruzzella V, Zoccolella S, Amati A, Torraco A, Lamberti P, Carnicella F, et al. Cerebellar ataxia as atypical manifestation of the 3243A>G MELAS mutation. Clin Genet. 2004;65:64-5.

59. Younes-Mhenni S, Thobois S, Streichenberger N, Giraud P, Mousson-de-Camaret B, Montelescaut ME, et al. Mitochondrial encephalomyopathy, lactic acidosis and stroke-like episodes (MELAS) associated with a Fahr disease and cerebellar calcifications. Rev Med Interne. 2002;23:1027-9.

60. Breningstall GN, Lockman LA. Massive focal brain swelling as a feature of MELAS. Pediatr Neurol. 1988;4:366-70.

61. Taylor RW, Schaefer AM, Barron MJ, McFarland R, Turnbull DM. The diagnosis of mitochondrial muscle disease. Neuromuscul Disord. 2004;14:237-45.

62. Sakuta R, Honzawa S, Murakami N, Goto Y, Nagai T. Atypical MELAS associated with mitochondrial tRNA(Lys) gene A8296G mutation. Pediatr Neurol. 2002;27:397-400.
63. Brown GK. Congenital brain malformations in mitochondrial disease. J Inherit Metab Dis. 2005;28:393-401.

64. Majoie CB, Akkerman EM, Blank C, Barth PG, Poll-The BT, den Heeten GJ. Mitochondrial encephalomyopathy: comparison of conventional MR imaging with diffusion-weighted and diffusion tensor imaging: case report. Am J Neuroradiol. 2002;23:813-6.

65. Ulmer S, Flemming K, Hahn A, Stephani U, Jansen O. Detection of acute cytotoxic changes in progressive neuronal degeneration of childhood with liver disease (Alpers-Huttenlocher syndrome) using diffusion-weighted MRI and MR spectroscopy. J Comput Assist Tomogr. 2002;26:641-6.

66. Wolf NI, Seitz A, Harting I, Smeitink JA, Trijbels F, van den Heuvel LP, et al. New pattern of brain MRI lesions in isolated complex I deficiency. Neuropediatrics. 2003;34:156-9.

67. Argov Z, Arnold DL. MR spectroscopy and imaging in metabolic myopathies. Neurol Clin. 2000;18:35-52.

68. Bianchi MC, Tosetti M, Battini R, Manca ML, Mancuso M, Cioni $\mathrm{G}$, et al. Proton MR spectroscopy of mitochondrial diseases: analysis of brain metabolic abnormalities and their possible diagnostic relevance. Am J Neuroradiol. 2003;24:1958-66.

69. Gulati S, Shah T, Menon S, Jayasundar R, Kalra V. Magnetic resonance spectroscopy in pediatric neurology. Indian J Pediatr. 2003;70:317-25.

70. Jeppesen TD, Schwartz M, Hansen K, Danielsen ER, Wibrand F, Vissing J. Late onset of stroke-like episode associated with a 3256C-->T point mutation of mitochondrial DNA. J Neurol Sci. 2003;214:17-20

71. Kamada K, Takeuchi F, Houkin K, Kitagawa M, Kuriki S, Ogata A, et al. Reversible brain dysfunction in MELAS: MEG, and (1)H MRS analysis. J Neurol Neurosurg Psychiatry. 2001;70:675-8.

72. Lin DD, Crawford TO, Barker PB. Proton MR spectroscopy in the diagnostic evaluation of suspected mitochondrial disease. Am J Neuroradiol. 2003;24:33-41.

73. Moller HE, Kurlemann G, Putzler M, Wiedermann D, Hilbich T, Fiedler B. Magnetic resonance spectroscopy in patients with MELAS. J Neurol Sci. 2005;229-30

74. Moller HE, Wiedermann D, Kurlemann G, Hilbich T, Schuierer G. Application of NMR spectroscopy to monitoring MELAS treatment: a case report. Muscle Nerve. 2002;25:593-600.

75. Otsuki T, Kanamatsu T, Tsukada Y, Goto Y, Okamoto K, Watanabe H. Carbon 13-labeled magnetic resonance spectroscopy observation of cerebral glucose metabolism: metabolism in MELAS: case report. Arch Neurol. 2005;62:485-7.

76. Rango M, Bonifati C, Bresolin N. Parkinson's disease and brain mitochondrial dysfunction: a functional phosphorus magnetic resonance spectroscopy study. J Cereb Blood Flow Metab. 2006; 26:283-90.

77. Sciacco M, Prelle A, D'Adda E, Lamperti C, Bordoni A, Rango M, et al. Familial mtDNA T8993C transition causing both the NARP and the MILS phenotype in the same generation. A morphological, genetic and spectroscopic study. J Neurol. 2003; 250:1498-500.

78. Wilichowski E, Pouwels PJ, Frahm J, Hanefeld F. Quantitative proton magnetic resonance spectroscopy of cerebral metabolic disturbances in patients with MELAS. Neuropediatrics. 1999;30: 256-63.

79. Lodi R, Carelli V, Cortelli P, Iotti S, Valentino ML, Barboni P, et al. Phosphorus MR spectroscopy shows a tissue specific in vivo distribution of biochemical expression of the G3460A mutation in Leber's hereditary optic neuropathy. J Neurol Neurosurg Psychiatry. 2002;72:805-7.

80. Valentino ML, Barboni P, Ghelli A, Bucchi L, Rengo C, Achilli A, et al. The ND1 gene of complex I is a mutational hot spot for Leber's hereditary optic neuropathy. Ann Neurol. 2004;56: 631-41.

81. Sijens PE, Smit GP, Rödiger LA, van Spronsen FJ, Oudkerk M, Rodenburg RJ, et al. MR spectroscopy of the brain in Leigh syndrome. Brain Dev. In Press 2008.

82. José da Rocha A, Túlio Braga F, Carlos Martins Maia A Jr, Jorge da Silva C, Toyama C, Pereira Pinto Gama H, et al. Lactate detection by MRS in mitochondrial encephalopathy: optimization of technical parameters. J Neuroimaging. 2008;18: $1-8$. 
83. Bianchi MC, Sgandurra G, Tosetti M, Battini R, Cioni G. Brain magnetic resonance in the diagnostic evaluation of mitochondrial encephalopathies. Biosci Rep. 2007;27:69-85.

84. Saneto RP, Friedman SD, Shaw DW. Neuroimaging of mitochondrial disease. Mitochondrion. In Press 2008.

85. Dubeau F, De Stefano N, Zifkin BG, Arnold DL, Shoubridge EA. Oxidative phosphorylation defect in the brains of carriers of the tRNAleu(UUR) A3243G mutation in a MELAS pedigree. Ann Neurol. 2000;47:179-85.

86. Turconi AC, Benti R, Castelli E, Pochintesta S, Felisari G, Comi G, et al. Focal cognitive impairment in mitochondrial encephalomyopathies: a neuropsychological and neuroimaging study. J Neurol Sci. 1999;170:57-63.

87. Minnerop M, Kornblum C, Joe AY, Tatsch K, Kunz WS, Klockgether T, et al. Dopamine transporter SPECT in patients with mitochondrial disorders. J Neurol Neurosurg Psychiatry. 2005;76:118-20.

88. Peng NJ, Liu RS, Li JY, Tsay DG, Kong KW, Kwok CG, et al. Increased cerebral blood flow in MELAS shown by Tc-99m HMPAO brain SPECT. Neuroradiology. 2000;42:26-9.
89. Thajeb P, Wu MC, Shih BF, Tzen CY, Chiang MF, Yuan RY. Brain single photon emission computed tomography in patients with A3243G mutation in mitochondrial DNA tRNA. Ann N Y Acad Sci. 2005; 1042:48-54.

90. Luoma P, Melberg A, Rinne JO, Kaukonen JA, Nupponen NN, Chalmers RM, et al. Parkinsonism, premature menopause, and mitochondrial DNA polymerase gamma mutations: clinical and molecular genetic study. Lancet. 2004;364:875-82.

91. Damian MS, Hertel A, Seibel P, Reichmann H, Bachmann G, Schachenmayr W, et al. Follow-up in carriers of the 'MELAS' mutation without strokes. Eur Neurol. 1998;39:9-15. 